v. 01 , n. 01 : pp. $89-103,2005$ ISSN $1808-0448$
Revista Gestão Industrial

\section{AS ESCOLHAS DE CURSOS PELAS MULHERES: QUAL FORMAÇÃO PARA QUAIS PAPÉIS SOCIAIS? O CASO DAS ESTUDANTES DO CENTRO FEDERAL DE EDUCAÇÃO TECNOLÓGICA DO PARANÁ - UNIDADE DE PONTA GROSSA}

WOMEN'S COURSE CHOICES:

WHICH COURSE LINE FOR EACH SOCIAL ROLE? THE STUDENT'S CASE AT THE FEDERAL CENTER OF TECHNOLOGICAL EDUCATION OF PARANÁ (CEFET-PR) PONTA GROSSA UNIT

\author{
Nadia Veronique Jourdan Kovaleski ${ }^{1}$; Luiz Alberto Pilatti ${ }^{2}$ \\ ${ }^{1}$ CEFET-PR/Unidade de Ponta Grossa, kovaleski@ pg.cefetpr.br \\ ${ }^{2}$ CEFET-PR/Unidade de Ponta Grossa, lapilatti@pg.cefetpr.br
}

Recebido para publicação em: 14/11/2004

Aceito para publicação em: 23/02/2005

\title{
RESUMO
}

O presente estudo tem o objetivo de discutir a influência das relações sociais de sexo no momento da escolha de um curso superior através do depoimento das alunas dos Cursos Superiores de Tecnologia em Alimentos e Mecânica do Centro Federal de Educação Tecnológica do Paraná, Unidade de Ponta Grossa (CEFET-PR). Trata-se de um estudo exploratório que, em função dos procedimentos técnicos adotados, pode ser caracterizado como estudo de caso. Um estudo histórico (da Idade-Média até nossos dias) tenta fazer entender a relação mulher/instrução e mostra quais foram as sementes que permitiram a eclosão dos movimentos feministas. A relação da mulher com o saber é analisada e foi constatado que as mulheres sempre foram afastadas dos saberes teóricos e técnicos. Conclui-se que as escolhas de cursos pelas alunas do CEFET-PR, são ainda permeadas de muitos preconceitos, mas são escolhas muito racionais considerada a situação de desigualdade existente entre homens e mulheres atualmente.

Palavras-chave: Educação, mulheres, relações sociais de sexo.

\section{Introdução}

Essa pesquisa analisa que razões manifestam as alunas do primeiro semestre dos Cursos Superiores de Tecnologia em Alimentos e Mecânica do Centro Federal de Educação Tecnológica do Paraná (CEFET-PR) para a escolha desses cursos no vestibular de janeiro 2002 e, ao conhecer as motivações que as influenciaram, tenta entender por que aproximadamente $90 \%$ do efetivo de alunas se concentram no Curso de Tecnologia em Alimentos.

A hipótese que balizou todo o desenvolvimento do estudo é que, historicamente, as mulheres sempre foram excluídas do sistema do saber. Destarte, suas escolhas de cursos atuais são 
resultantes da sua subordinação nas esferas profissionais e familiares e de análises racionais do sistema social ao qual estão inseridas.

O grande século, para a instrução das mulheres, é o século XX. Por exemplo, a França que apresentava 624 estudantes de sexo feminino em 1900 passou a ter mais de 520.000 em 1990, sendo aproximadamente 70.000 a mais que os estudantes de sexo masculino ${ }^{1}$. No Brasil, no ano 2000, dos 2.694.245 estudantes universitários, 1.515 .352 são mulheres ${ }^{2}$. As modificações progressivas dos currículos que apagam as distinções entre os ensinos ofertados a cada sexo e as disposições jurídicas que fazem desaparecer as segregações em proveito da escola mista são só os sintomas. Eles acompanham mais a evolução do que a preparam. A este respeito Baudelot ${ }^{3}$ comenta que o movimento é testemunha de uma transformação profunda das mentalidades e não só de uma simples moda ideológica que redundaria numa minoria.

Segundo Mosconi assiste-se a um melhor sucesso escolar das mulheres, no entanto persiste uma forte diferenciação sexuada, dependendo dos estudos escolhidos, como se o desaparecimento da desigualdade vertical acentuasse a desigualdade horizontal ${ }^{4}$. Sobre trinta e seis países pesquisados por Baudelot, a engenharia, a arquitetura, a matemática, as ciências e o direito são orientações masculinas dominantes em vinte e nove países; letras, ciências humanas, medicina, são orientações femininas dominantes em trinta países. ${ }^{5}$ Ao estudar esta revolução da educação das mulheres depara-se com dois fatos sociais, cujas orientações são contraditórias:

uma progressão espetacular da escolaridade feminina;

uma permanência das segregações entre mulheres e homens no termo e no coração da escolaridade.

Dessas duas forças contraditórias, qual é a resultante? O progresso das mulheres na escola constitui um fato social fundamental suscetível de transformar a divisão entre os sexos e uma parte do regime econômico-afetivo milenar, ou trata-se de modificações limitadas cujos efeitos só levariam as barreiras mais 'para cima'?

Nesse estudo procurou-se entender, num primeiro momento, como os indivíduos constroem a sua relação com o saber. O livro de Berger e Luckmann A construção social da realidade trata justamente dessa relação ${ }^{6}$. Procurou-se então, nesse livro, entender como as mulheres constroem a sua relação com o saber. Num segundo momento será discutida, historicamente (da Idade Media até nossos dias), a relação das mulheres com a instrução, usando a

\footnotetext{
${ }^{1}$ (BAUDELOT; ESTABLET, 1992).

2 INSTITUTO NACIONAL DE ESTUDOS E PESQUISAS EDUCACIONAIS (ANÍSIO TEIXEIRA, 2002).

${ }^{3}$ (BAUDELOT; ESTABLET, 1992).

${ }^{4}$ (MOSCONI, 1994).

5 (BAUDELOT; ESTABLET, 1992).

${ }^{6}$ (BERGER; LUCKMANN, 1999).
} 
tipologia de Berger e Luckmann isto é, classificando as sociedades em dois tipos, monopolista e pluralista ${ }^{7}$. E, enfim, num terceiro momento, o estudo de caso será apresentado.

\section{A relação das mulheres com o saber}

Os escritos de Berger e Luckmann possibilitam a dedução de três postulados implícitos em relação às mulheres. Inicialmente, o saber é produzido pelos grupos sociais dominantes. Em segundo, as mulheres fazem parte, naturalmente, dos grupos dominados. Essa dominação é concebida como 'pré-social', anterior à organização social ${ }^{8}$. Isto é, a dominação é natural. A partir desses dois postulados, pode-se deduzir o terceiro sem dificuldade: as mulheres são, naturalmente, excluídas da produção dos saberes. Isso explica porque essa questão não é teorizada no livro, é uma questão sem objeto.

É muito interessante para o objeto em estudo - a relação das mulheres com o saber - notar que Berger e Luckmann sempre dão exemplos ligados à divisão social do trabalho. Os autores não consideram a divisão sexual do trabalho que, ao determinar tarefas e papéis diferentes para os homens e as mulheres, define também domínios de competência e conhecimento diferentes segundo os sexos. Entende-se o porquê quando os autores afirmam: "Esta atribuição pode basear-se em diferenças pré-sociais, tais como o sexo, ou em diferenças produzidas no curso da interação social, por exemplo, as que são produzidas pela divisão do trabalho"'9.

O que significa a oposição entre diferença sexual 'pré-social' e diferença social gerada pela divisão social do trabalho? É certo que a divisão sexual é pré-social num sentido biológico, mas é uma razão suficiente para pensar que ela estabelece uma divisão das atividades também pré-social, isto é, natural? De onde provém que a diferença das tarefas e dos papéis entre os sexos não é compreendida como uma divisão do trabalho? É difícil pensar que as tarefas domésticas e educativas para as quais as mulheres são, geralmente, destinadas não são um trabalho no mesmo título que as tarefas masculinas.

Tudo acontece como se a concepção histórica da produção do social parasse nos limites da divisão sexual e se recusasse a ver nela uma divisão não criada a partir do nada, claro, mas, socialmente construída pela repartição das atividades e das tarefas e pelas interações entre os indivíduos dos dois sexos. O lugar das mulheres nos saberes é situado em nível das tarefas pragmáticas da vida cotidiana e não em nível da legitimação e da teoria pura. As mulheres não têm

\footnotetext{
${ }^{7}$ (BERGER; LUCKMANN, 1999).

${ }^{8}$ (BERGER; LUCKMANN, 1999, p. 91).

9 (BERGER; LUCKMANN, 1999, p. 91).
} 
lugar entre os criadores de mito e o corpo de especialistas dos "mecanismos conceituais específicos da manutenção do universo" ${ }^{10}$.

Mosconi comenta que até hoje a metade masculina da humanidade teve o quase monopólio desses 'mecanismos conceituais da manutenção do universo' com os quais uma sociedade se dá as representações e legitimações de si mesma e da sua ordem social ${ }^{11}$. Muitos desses saberes apresentaram-se como universais mesmo quando exprimiam o ponto de vista dos homens como grupo dominante. Segundo Mosconi, essa situação teve duas conseqüências para a instrução das mulheres. Em primeiro lugar, ao instruírem-se, as mulheres não tiveram acesso a saberes produzidos por indivíduos do seu sexo, mas a saberes produzidos por homens que, muitas vezes, davam-lhes imagens desvalorizadas do seu sexo. Portanto, nada ou pouca coisa nesses saberes permitiram pensar, compreender e teorizar a sua própria experiência, a sua própria situação social, o seu próprio lugar nas relações sociais de sexo ${ }^{12}$.

\section{A relação histórica das mulheres com a instrução}

A Idade Média é considerada uma sociedade monopolista religiosa, isto é, a religião possui um monopólio simbólico efetivo. Essa sociedade supõe uma divisão social (e não somente sexual) do trabalho desenvolvido e, em conseqüência, uma importante diferenciação na estrutura social, com excedentes econômicos.

Existe uma união dos poderes religiosos e políticos. Cada detentor de um poder é uma autoridade no sentido, ou seu poder tem uma origem sagrada e/ou as legitimidades emanam do poder transcendental da divindade. Neste sistema, as mulheres são fechadas na família, excluídas de todos os poderes e submetidas à dominação dos homens, que exercem um estreito controle sobre sua sexualidade. A esse respeito, é interessante notar que as principais categorias femininas que se sobressaem durante toda a Idade Média são as virgens, as mulheres casadas e as viúvas. O trabalho, o poder, a riqueza, a cultura, o lugar de habitação, a proveniência social ou geográfica mantêm-se sob critérios estranhos, ou pelo menos não decisivos quando aparecem, para se compreender o mundo das mulheres ${ }^{13}$.

As mulheres são, para os homens, bens que trocam para criar alianças. A moça, primeiro sob autoridade do pai, é dada a um marido de quem se torna propriedade. Ele lhe destina as tarefas e papéis e lhe confisca todo poder sob suas atividades procriativas, econômicas e sociais. Dessa subordinação decorre a sua situação em relação aos saberes já que somente aqueles que detêm uma autoridade religiosa podem ser habilitados a tomar a palavra, a pensar e a interpretar os textos

\footnotetext{
${ }^{10}$ (BERGER; LUCKMANN, 1999).

11 (MOSCONI, 1994).

12 (MOSCONI, 1994).

${ }^{13}$ A mulher sob custódia. In: (DUBY; PERROT, 1993).
} 
sagrados. As mulheres, ao mesmo tempo em que são excluídas de todo poder, são também excluídas dos saberes.

A situação pluralista supõe uma sociedade urbana, com uma divisão do trabalho altamente desenvolvida. Em termos práticos, implica numa forte diferenciação nas estruturas sociais e numerosos excedentes econômicos que liberam grupos sociais inteiros das tarefas de subsistência. Essas condições são típicas das sociedades industriais modernas, mas já existiram em certos setores das antigas sociedades.

Nessa sociedade pluralista produz-se uma transformação dos mecanismos conceituais da realidade. À religião e à teologia acrescentam-se conceitos filosóficos e científicos do mundo e da sociedade. A teologia, a filosofia e a ciência eram propriedades de um corpo masculino de especialistas que tendiam a excluir as mulheres. Nas sociedades pluralistas, essa tendência vai se chocar com um movimento inverso oriundo dos grupos das mulheres, porque é na sociedade pluralista que, segundo Berger, aparecem as ideologias e os intelectuais ${ }^{14}$. Uma ideologia representa uma definição particular da realidade, ligada a um interesse concreto de poder. Um intelectual é um tipo de especialista cujos estudos não estão ao alcance de toda sociedade, e pode-se considerá-los como marginais. Pode-se dizer que nas sociedades industriais modernas, os movimentos feministas fazem parte desses subgrupos de intelectuais. As feministas são mulheres que recusam a definição oficial da realidade social imposta pelos especialistas masculinos conforme com os interesses do seu grupo de sexo.

Os historiadores da educação brasileira que abordaram o tema da educação feminina demonstram que a educação escolarizada para as mulheres não tinha sido uma preocupação da sociedade patriarcal brasileira até meados do século XIX.

De fato, o patriarcalismo brasileiro caracterizou-se por uma severa clausura doméstica das mulheres, costume herdado da Península Ibérica e, conseqüentemente, dos árabes ${ }^{15}$. Depoimentos de viajantes estrangeiros que percorreram o Brasil no século XIX, como Saint-Hilaire e Max Leclerc, informam-nos das mulheres analfabetas, ignorantes, arredias, que se ocultavam atrás das portas e evitavam contato com estranhos, voltadas para a criação dos filhos, a direção da casa e dos escravos domésticos ${ }^{16}$.

No entanto, os acontecimentos do final do século XVIII na Europa trouxeram novos ares que impregnaram a sociedade brasileira. Segundo Manoel, a sociedade (a oligarquia, sobretudo) percebeu que não era mais possível manter suas filhas no mesmo grau de ignorância e isolamento em que viviam, estado incompatível com a sociedade brasileira que se urbanizava, abria-se ao contato com a cultura e o mundo moderno. Convém salientar que o termo urbanizar, neste momento

\footnotetext{
${ }^{14}$ (BERGER; LUCKMANN, 1999).

15 (MAURO, 1980).

${ }^{16}$ (MANOEL, 1996).
} 
preciso da história brasileira, não significava apenas a criação de cidade, mas indicava, sobretudo, a penetração da moderna cultura burguesa e das relações capitalistas em todos os níveis ${ }^{17}$.

Mas que tipo de instrução?

$\mathrm{Na}$ verdade, a grande questão era: como educar, conforme as exigências do mundo moderno, sem deixar o lado subversivo dessa modernidade corromper a alma feminina? Porque se a palavra 'moderna' significava máquinas, eletricidade, bancos, ferrovias, significava também extensão de direitos civis para todos, inclusive as mulheres. E dos fantasmas da modernidade: “o que mais assombrava a oligarquia brasileira [...] eram justamente essas primeiras manifestações de um movimento feminista" ${ }^{\prime 18}$. Intelectuais de extração liberal e positivista, como Teixeira Mendes, Tito Lívio de Castro e José Veríssimo, embora aceitassem a educação feminina, recomendavam que ela não ultrapassasse os limites da formação de donas-de-casa e mães de família. Mas foi o grupo dos católicos que tinha a maior repulsa pela emancipação feminina.

O Barão de Rio Branco definiu um projeto de 'revolução dentro da ordem' para a educação feminina cujas disciplinas seriam prendas domésticas para formar damas prendadas e boas donasde-casa. Em defesa dessa proposta dizia ele: "Nada de reviver as loucas e funestas tentativas de Catharina Teot e Olympia de Gouges, fundadoras das Mulheres Livres, e outras notabilidades femininas, que pretendem emancipar-se da tutela dos homens e aspiram aos mesmos empregos e direitos que eles"19. Manoel comenta que a oligarquia brasileira pressionada pela necessidade da educação e pela liberdade feminina escolheu aliar-se ao catolicismo conservador e entregar-lhe suas filhas para educar.

Os séculos XIX e XX contabilizaram incríveis conquistas coletivas no campo social e político para as mulheres. Porém, pode-se dizer que a maior revolução de costumes de que se tem notícia está ainda balbuciante. Falta muito caminho para que a interação homem/mulher faça-se na igualdade. Na educação é flagrante o desequilíbrio existente entre os cursos, as mulheres como os homens continuam acuados a certas escolhas. Um dos temas recorrentes a respeito da instrução das mulheres é que os saberes eruditos não são feitos para elas: “A pesquisa das verdades abstratas e especulativas, dos princípios, dos axiomas nas ciências, tudo que tende a generalizar as idéias não é da competência das mulheres, os seus estudos devem se relacionar com a prática"20.

$\mathrm{Na}$ primeira metade do século XX, a educação das mulheres das camadas populares se resumia às prendas domésticas e ensinos das primeiras letras. As filhas da oligarquia recebiam um tipo de instrução semelhante, mas às prendas domésticas eram acrescidas uma certa instrução artística, uma leve cultura literária e as normas de etiquetas essenciais para o convívio social.

\footnotetext{
${ }^{17}$ (MANOEL, 1996).

18 (MANOEL, 1996, p. 30).

${ }^{19}$ (PARANHOS, 1953 ; apud MANOEL, 1996, p. 31).

${ }^{20}$ (ROUSSEAU, 1966, p. 537-538).
} 
$\mathrm{Na}$ França, os trabalhos de agulha serão ensinados nas escolas até a Segunda Guerra Mundial, mas o movimento feminista que eclodiu na América do Norte e na Europa, com repercussões na América Latina, encarregou-se de sepultar definitivamente a visão medieval da instrução feminina como contaminadora da consciência e perigosa para a pureza do corpo e da alma das mulheres.

Apesar disso, a educação e a profissionalização que acabaram conquistadas, embora muito parcialmente porque restritas a determinadas profissões, revelaram-se como mais um mecanismo de opressão.

Estudando dados da UNESCO sobre o ensino superior em mais de quarenta países, Baudelot mostra que existe ainda uma persistência universal dos modelos fortemente sexistas de orientação $^{21}$. Nenhum país escapa a esses modelos: na engenharia uma forte dominação dos homens e nos estudos literários uma forte dominação feminina.

É interessante notar que as distâncias não diminuem entre os sexos, como deveria ser o normal. Ao contrário, elas aumentam. Segundo os estudos de Baudelot, quando o número de mulheres cresce na universidade, elas aumentam a sua presença em todos os cursos, mesmo nos cursos tradicionalmente masculinos, mas, ao mesmo tempo, os homens aumentam a sua presença nos cursos masculinos e reduzem-na nos cursos mais femininos ${ }^{22}$.

Nos Estados Unidos, por exemplo, observa-se uma divisão entre uma graduação masculina voltada para a prática, o comando das coisas e dos homens, e uma graduação feminina orientada para a relação, à educação e à saúde. O mesmo poderia se dizer no Brasil.

\section{O caso das estudantes do Centro Federal de Educação Tecnológica do Paraná - unidade de Ponta Grossa}

O estudo desenvolveu-se através de uma pesquisa qualitativa com a aplicação de dez entrevistas semi-estruturadas a cinco alunas de Alimentos e cinco alunas de Mecânica. O objetivo da pesquisa foi conhecer as razões das suas respectivas escolhas e, sobretudo, entender porque que as alunas concentram-se no curso de Alimentos.

A seleção das entrevistadas foi aleatória, isto é, foi determinada a partir da tabela dos números dígitos. Não ter feito uma pré-seleção permitiu aproximar-se da objetividade que o pesquisador deve tentar respeitar, mas pode também afastar totalmente a pesquisa das hipóteses emitidas e dar um novo sentido ao estudo. Não foi o caso neste estudo. De um lado foi um pouco

\footnotetext{
${ }^{21}$ (BAUDELOT; ESTABLET, 1992).

${ }^{22}$ (BAUDELOT; ESTABLET, 1992).
} 
decepcionante. A média de idade das entrevistadas era de 19 anos, e esperava-se um pouco mais de independência em relação à família, menos preconceitos.

A fim de respeitar o anonimato das entrevistadas os seus nomes foram codificados por ' $\mathrm{A}$ ' de Alimentos e 'M' de Mecânica seguido do número da entrevista.

As interpretações das falas que, a fim de atender aos objetivos da pesquisa e facilitar a organização dos resultados, estruturam-se a partir das categorias a repartição do trabalho doméstico e educativo e as escolhas de cursos pelas alunas que vêm a seguir.

\section{A repartição do trabalho doméstico e educativo}

Nos depoimentos das alunas ficou muito claro que hoje o trabalho doméstico e educativo é reservado unicamente às mulheres. Para a maioria das entrevistadas, não casadas, o trabalho doméstico e educativo é feito pela mãe, com a ajuda, muitas vezes, das próprias entrevistadas. Das duas entrevistadas casadas, uma só diz ter a ajuda do marido e a outra assume sozinha as tarefas domésticas apesar de trabalhar e estudar à noite. Duru Bellat comenta a esse respeito que hoje é clássico e muito frequiente nos debates, nas análises, considerar como indissociáveis o trabalho das mulheres e o dever da família. Mas é somente com as mulheres que trabalho e família são percebidos como indissociáveis e muito poucos estudos empíricos sobre o trabalho dos homens têm a idéia de tomar em consideração o tamanho da família ou a atividade da esposa ${ }^{23}$.

Por exemplo, nas entrevistas de mulheres com cargo de chefia ou empresárias, uma das primeiras perguntas muita vezes é: 'Como que a senhora concilia o seu trabalho e a vida familiar?' Jamais essa pergunta é feita aos homens.

Quando foi perguntado às entrevistadas se a vinda de um filho poderá prejudicar a sua vida profissional, o primeiro impulso de quase todas elas foi de responder que não, mas no final das suas falas chegaram à conclusão que irá prejudicá-las. Várias delas sentiram que iriam prejudicá-las duplamente porque ou a vida familiar ou a vida profissional poderia ser preterida. Esse fato decorre que as entrevistadas analisam a maternidade como sendo um encargo unicamente da mulher. Em nenhum depoimento, a ajuda do pai é considerada. Isso demonstra perspicácia da parte das entrevistadas, elas não têm ilusões sobre sua vida futura: "É obvio que você vai precisar de um tempo, uma freada, para você se dedicar ao teu filho, afinal criança exige cuidados [...] Mas pode prejudicar a carreira porque um homem não vai precisar parar sua a carreira para ser pai, já uma mulher sim" (Entrevistada M1).

Toda 'mulher que trabalha' conhece bem as constantes preocupações profissionais e familiares: quem não fez a lista das compras ou programado as ocupações dos filhos entre duas

\footnotetext{
${ }^{23}$ (DURU-BELLAT, 1990).
} 
reuniões? É esta 'vida em dois' que caracteriza a relação com o tempo da mãe ativa, e faz com que não exista no seu planejamento tempos mortos. Entre a saída do seu trabalho e a volta para casa, o homem pode tomar um tempo para si mesmo, mas a mulher apressa-se rumo às preocupações familiares que, na verdade, ela não deixou e nas quais ela se envolve sem transição.

A noção de jornada dupla é falsa porque, na verdade, não são tarefas que se adicionam, mas é um conjunto de tarefas que são delegadas à mulher. O seu tempo não lhe pertence e não pode ser alugado inteiramente, sem culpabilidade num investimento profissional ou pessoal. Isso é relatado pelas entrevistadas M6 e A10 respectivamente:

- $\quad$ "Em certos aspectos pode prejudicar, porque quando a criança fica doente, a mulher ela tem mais estabilidade emocional para cuidar da família [...] e prejudica porque se a mulher trabalha ela vai precisar faltar emprego, já tem a preocupação com a família, com casa, com marido daí ela acaba de repente se importando demais com a família que é obviamente o mais importante para ela e ela acaba deixando de lado o emprego" (Entrevistada M6).

- $\quad$ "Eu pretendo sempre ser atualizada, indo para frente, sendo das melhores, acho que parando vai prejudicar nisso [...] mas se eu fico trabalhando prejudica em casa” (Entrevistada A10).

A culpabilidade atestada pela entrevistada A2 constitui um outro fator que pesa sobre a 'disponibilidade mental' ou a serenidade com as quais a mulher pode investir no seu trabalho:

- $\quad$ É difícil você tendo que trabalhar, mas deixando teu filho de lado, pensando: "Puxa! Eu deixei meu filho em casa, podia curtir ele" (Entrevistada A2).

Considera-se que o acesso a todos os estudos e a co-educação no sistema escolar correspondeu a uma mudança do modelo social da divisão do trabalho entre os sexos. No século XIX, o modelo tradicional destinava aos homens o trabalho produtivo (profissional) e às mulheres, o trabalho doméstico e reprodutivo (dona de casa). O trabalho das mulheres pobres aparecia mais como uma obrigação devido à miséria. Hoje, comenta Mosconi, o novo modelo dominante afirma que as mulheres devem também participar do trabalho produtivo e que essa participação é essencial: "Hoje o modelo dominante não é mais da escolha (trabalhar ou ter filho), nem aquele da alternância (trabalhar, parar, trabalhar de novo), mas aquele do acúmulo (trabalhar e no mesmo tempo ter filhos), ${ }^{, 24}$.

A partir de então, as finalidades do sistema escolar se transformam para as mulheres: devem ir à escola não somente para instruir-se, mas para adquirir uma formação profissional.

Uma pergunta surge: quem vai assumir o trabalho doméstico e educativo?

Deve-se reconhecer que nossa sociedade não deu uma resposta clara à pergunta. A resposta dominante, mais ou menos implícita, diz que são as mulheres que devem conciliar as duas formas

${ }^{24}$ (MOSCONI, 1994, p. 234). 
de trabalho. Tudo isso é claro entre as entrevistadas: todas elas querem trabalhar e só falam em diminuir um pouco o trabalho na vinda de um filho e usar os serviços de creche ou babá.

Nessa situação, as mulheres são duplamente penalizadas. Na família, onde executam gratuitamente o trabalho educativo e doméstico; na vida profissional, onde o acúmulo das duas formas de trabalho não as tornam suficientemente disponíveis para pretender às mesmas carreiras que os homens. As entrevistadas são conscientes dessa situação e sentiu-se nas suas falas o conflito doloroso em que vivem. Elas se preparam, tanto quanto os homens, para ter uma boa profissão, mas sabem que, a partir do momento que terão filhos, será difícil progredir na profissão, justamente por causa do acúmulo dos trabalhos domésticos e profissionais.

De fato, o desafio para as mulheres não é conciliar família e trabalho, como dizem os discursos oficiais, mas compensar o fato de trabalhar ou, reciprocamente, serem perdoadas por terem filhos.

\section{As escolhas de cursos pelas alunas: racionalidades, determinações, crenças, preconceitos e medos}

Nota-se uma mistura de racionalidade, determinações, crença e preconceitos nas respostas das entrevistadas a estas quatro perguntas: 'Como você escolheu o seu curso atual?'; 'No momento de escolher o curso do CEFET-PR, o que te influenciou mais? Por quê?'; 'Nas disciplinas que você cursou até hoje, algumas lhe parecem mais adequadas ao sexo masculino ou ao sexo feminino?'; 'Como você explica o fato de, no CEFET-PR, os cursos de Mecânica, Eletrônica e Informática sejam, essencialmente, masculinos e o Curso de Alimentos seja, essencialmente, feminino?'.

Em muitas respostas à primeira pergunta, as entrevistadas dizem que escolheram este curso porque iriam se dar bem. Como interpretar essa expressão ‘se dar bem'? A primeira interpretação que vem à mente é ter sucesso nos estudos, mas, com certeza, essa expressão quer dizer também achar um emprego com facilidade e, sobretudo, um emprego condizente com seu lugar na sociedade. Essa expressão ‘se dar bem' pode demonstrar que a escolha das alunas é racional. Para Duru-Bellat:

Hoje, em vista das ofertas de emprego mais prováveis, as orientações atuais das mulheres parecem muito razoáveis e não se vê o interesse para que elas se tornem pioneiras. De fato, quando elas começam em uma formação tradicionalmente masculina, elas se expõem a maiores dificuldades de inserção social e profissional, caso se contentassem com formação mais feminina. ${ }^{25}$

Nota-se que as entrevistadas que usaram a expressão 'se dar bem' são do curso de Alimentos. As entrevistadas que escolheram o curso de Mecânica destacam-se pela determinação:

${ }^{25}$ (DURU-BELLAT, 1990, p. 197). 
- $\quad$ "Eu sempre quis fazer uma coisa na área de engenharia [...] Ah! Eu vou fazer Alimentos porque tenho vergonha de ficar numa sala de aula com quarenta meninos... Não! Eu acho que você tem que ir pelo que você gosta, afinal de contas é o que você vai fazer o resto da tua vida [...] Eu sabia que era aquilo que eu queria" (Entrevistada MI).

A mesma entrevistada é consciente das dificuldades que sua escolha curricular pode provocar:

- $\quad$ "É obvio que o mercado nessa área, mecânica, engenharia de produção é totalmente aberto para homens, eu desconheço mulher que seja chefe de produção. Acredito que até me formar e fazer pós-graduação, isso muda. Eu acredito também e isso é obvio, hoje uma empresa prima pela qualidade, e não vai me dizer você é mulher: eu sinto muito! Ela vai analisar o meu currículo, vai analisar o currículo de outros e que se eu for melhor, eu tô dentro, não sei se é uma utopia da minha parte, mas eu acredito, tenho fé" (Entrevistada M1).

É interessante notar que ela já planejou fazer uma pós-graduação, isto pode demonstrar conhecimento que, a um certo nível de qualificação o que conta é a competência e ela aposta nisso.

Mesmo com essa racionalidade e determinação, persiste uma crença em diferenças numerosas e determinadas entre homens e mulheres. Várias entrevistadas são convencidas que mulheres e homens são dotados de aptidão e interesse muito diferentes, o que justifica diferenças de currículo e de escolha de vida:

- "Homem se dá melhor em exatas, Matemáticas essas coisas assim, mulher gosta mais de Biologia, Química. Homens gostam sempre de Física” (Entrevistada A8).

“Tem algumas matérias eu não sei porquê, mas a visão geral é essa: que cálculo é mais para meninos, não sei porque mais eles têm mais facilidade e meninas é mais em relação a História, Geografia, Ciências, matérias com mais teorias e eles não, para eles é cálculos" (Entrevistada A2). As explicações para justificar a dicotomia feminino/masculino nos cursos do CEFET-PR apresentam diferentes preconceitos. Existe o preconceito para com as mulheres que fazem o curso de Mecânica, pois isso rompe com muitas das representações feitas sobre as mulheres desde tempos remotos: a mulher é um ser delicado, frágil, sem força física. Mas existe também o preconceito em deixar uma mulher estudar numa sala com um grande número de homens:

- $\quad$ "Eu acho que isso é um pouco de preconceito dos próprios alunos ou da família, por exemplo: 'eu não vou deixar minha filha fazer mecânica, só tem homem, então vai aprender muitas bobagens [...] Eu tenho uma amiga que fazia mecânica, o pai dela falou que era para ela desistir do curso porque tinha quarenta homens na sala" (Entrevistada M9). 
- $\quad$ "Eu me lembro que a primeira pergunta que a professora fez na aula que a gente teve de processo de fabricação seria o porquê das meninas escolheram mecânica, segundo os meninos, eles disseram que era para ficar no meio deles" (Entrevistada M5).

Existe também o preconceito contra o homem que quer estudar Alimentos, que não é um curso tão viril (Alimentos é coisa de mulher!) como Mecânica ou tão intelectual como Eletrônica. O desconhecimento dos conteúdos dos cursos é um ponto interessante evocado pelas entrevistadas. Tal fato leva a crer que a Instituição julga desnecessárias campanhas de informação sobre o conteúdo real dos cursos. Com certeza, a escola é vista como sendo mais masculina pelos próprios dirigentes.

Diz a entrevistada A4 para justificar o fato de ter escolhido o curso de Alimentos em lugar do curso de Eletrônica que era o curso desejado:

- "Quando eu vim aqui escolher eu pensei em fazer eletrônica também, só que em eletrônica só tem rapazes e alimentos é mais mulheres. [...] eu sou muito tímida então numa sala só com rapazes na hora de uma apresentação [...] eu não ia conseguir porque eu sou muito tímida demais e só com meninas é diferente, a gente se abre melhor, é mulher, então você não liga muito o que estão pensando, quando é homem você fica mais... apreensiva, você liga mais para o que eles estão pensando de você".

A influencia do julgamento dos homens parece ser uma realidade que pode influenciar no momento de uma escolha. Entretanto, na fala da aluna pode-se identificar também a importância de escolher um curso que muitos alunos do mesmo sexo escolheram, sobretudo no momento crucial da adolescência onde acaba a construção da identidade sexual.

$\mathrm{O}$ fato de escolher um curso implica em que esse desejo e a atividade que ele inspira estejam de acordo com uma certa representação de si mesma, uma certa imagem de si mesma. A escolha não se faz na solidão, ela se faz, por exemplo, em estreita ligação com as esperanças familiares. Essas esperanças são, elas mesmas, organizadas pelas idéias, crenças e preconceitos. Se existem dissonâncias entre o projeto pessoal e as esperanças familiares ou docentes, essa escolha poderá provocar um conflito. As atitudes positivas ou negativas dos familiares podem conduzir à renuncia do querer se apropriar de tal ou tal saber:

- "Se eu tinha escolhido mecânica a minha família não ia aceitar muito bem, ia ficar com receio e preconceitos" (Entrevistada A9).

Como explicar o receio, o medo (evocado pela mesma entrevistada) que a família ou a aluna podem sentir ao fazer um curso tradicionalmente masculino? Podemos relacioná-lo ao olhar da sociedade que até há poucos anos condenava de maneira irrevogável as mulheres que transgrediam a divisão sexual do trabalho. As estudantes de Mecânica relatam a surpresa das pessoas de fora da escola quando dizem que estudam Mecânica: 
“O que você faz, faz Alimentos? Não, faço Mecânica. 'Nooossa!’” (Entrevistada M1).

A mulher que feria (que fere?!) a divisão sexual do trabalho era vista também como uma pessoa que transgredia os ' bons costumes'. A questão da sexualidade é subjacente também a esse medo, esse receio. Uma mulher que gosta de 'mexer na graxa' é vista como alguém que pode ter uma sexualidade duvidosa, será que vai gostar de homem?!

A família é uma categoria subjacente a esse estudo. Devido à riqueza do tema, esboçam-se algumas considerações. Vê-se a seguir como essa categoria é evocada nas entrevistas:

- $\quad$ "Meus pais eram contra de eu fazer Mecânica, até o terceiro ano que eu cursei o técnico, eles eram contra. Principalmente meu pai, ele sempre me criticava, que eu não ia conseguir progredir, trabalhar dentro da profissão, me especializar em parte nenhuma. Depois que eu consegui o primeiro emprego como técnica em mecânica, eles passaram a acreditar em mim, agora eles me apóiam" (Entrevistada M5).

- $\quad$ "Mas eu fiz um ano de Alimentos porque minha mãe não queria e se eu fizesse Mecânica minha mãe diz que não ia me deixar estudar aqui [...] daí eu passei em Mecânica e minha mãe aceitou, daí o primeiro ano que estava cursando, entrei em março e maio eu consegui emprego na área de mecânica, daí ela achou a coisa mais maravilhosa do mundo!” (Entrevistada M3).

- "Os meus pais influenciaram bastante na questão da opinião de escolher o curso" (Entrevistada A2).

Quer seja nas sociedades pré-modernas ou na atual, a família é uma instituição-chave, e a mulher, como lembra Carvalho ${ }^{26}$ encontra na família um dos seus principais papéis. Nas sociedades pré-modernas o patriarcado não designava somente uma forma de família fundada sobre a 'potência masculina'. Ele era também a expressão de um sistema político apoiado em nossas sociedades, na Teologia. A Revolução Francesa foi o primeiro golpe mortal contra o patriarcado mas, na verdade, os 'revolucionários' queriam se livrar do patriarcado político, mantendo o patriarcado familiar.

$\mathrm{Na}$ maioria das sociedades ocidentais, o sistema patriarcal recebeu o golpe de graça nestes últimos trinta anos, ponto minúsculo na linha da evolução humana, os anos 60/90 transformaram a relação entre mulheres e homens.

Entretanto, nas falas das entrevistadas pode-se sentir que se vivem, por enquanto, momentos de transição. A influência da família (muitas vezes na figura do pai) ainda é grande e condicionam as suas escolhas, mas desenham-se também novos relacionamentos que continuarão a 'apagar' a família tradicional para a emergência de um novo tipo de família. As entrevistadas estão longe do modelo da mãe que 'casou, engravidou e parou de estudar'. Algumas delas já planejaram o momento de casar e engravidar. Entretanto, todas são unânimes: a primeira preocupação é de ter uma profissão.

\footnotetext{
${ }^{26}$ (CARVALHO, 1997).
} 


\section{Conclusões}

A hipótese que orientou o presente estudou foi que a escolha de curso pelas estudantes do CEFET-PR era resultante da sua subordinação nas esferas profissionais e familiares e de análises racionais do sistema social no qual estão inseridas.

De fato, todas as entrevistadas sabem que elas vão acumular duas formas de trabalho: o doméstico e educativo e o de fora de casa. Todas elas sabem também que a vinda de um filho tem efeito diferente sobre a carreira masculina e a feminina: conforta mais ainda o homem a investir na carreira e coloca em risco a carreira da mulher e mesmo o simples direito a ter um emprego.

Vista pela ideologia sexista, essa situação tem duas vantagens: os homens continuam a não serem incomodados pelo trabalho doméstico e educativo e, com a marginalização da mulher no mercado de trabalho, evitam a concorrência com ela nos empregos e carreiras. Esta concepção do trabalho das mulheres toca um ponto 'nevrálgico' das relações de força e de poder entre homens e mulheres que nem o regime comunista da URSS conseguiu modificar.

As mulheres de hoje acham-se numa encruzilhada: de um lado existe um discurso oriundo da família e da sociedade que as pressionam a adquirir diplomas e profissões 'como os homens', e de um outro lado existe uma injunção implícita veiculada pela sociedade que diz: 'sejam femininas', isto é, antes de tudo sejam 'boas mães de família e continuem a assumir o trabalho doméstico'. Transgredir esse implícito não é senão o apanágio de uma minoria de mulheres melhor dotadas em termos escolares e sociais que as outras.

Neste contexto, escolher um curso mais feminino parece ser mais racional. Por que acrescentar mais dificuldades ainda a uma inserção profissional que já é mais problemática para as mulheres?

Será que a diplomação pode fazer a diferença como acredita a entrevistada M1? Acreditase que não. É uma ilusão pensar que as mulheres poderão mudar a sua condição social e profissional por uma simples mudança de orientação escolar. É o conjunto das relações sociais entre os sexos que precisaria transformar, quer seja na área profissional (com uma real misticidade dos empregos) ou na área familiar (com uma real divisão das tarefas domésticas e educativas) e uma tal transformação só poderia acontecer por uma ação coletiva política. Somente uma transformação da organização econômica e social vigente poderia criar 'um novo contrato entre iguais'.

\section{ABSTRACT}


This study discusses the influence o gender social relations at the moment at high-education level course must be chosen by means of a research with undergraduate Food Technology and Mechanics students from Centro Federal de Educação Tecnológica do Paraná, Campus of Ponta Grossa (CEFET-PR). It was our intention to understand the outstanding gender numerical inequality in the Food and Mechanics courses. A historical study (from Middle Age up to the present day) sheds lights upon the relation woman/instruction and pinpoints the causes that triggered women's liberation movements. Woman's relation with education is analyzed and it was verified that women have always been kept away from theoretical and technical knowledge has been reached. It is an exploratory study that, due to the adopted technical procedures, has been characterized as a study case. The data collection was carried out by means of a semi-structured interview. We conclude that even though prejudice is still present when students from CEFET-PR are confronted with choosing a course, they make rational choices taking into consideration the current existing situation of inequality between men and women.

Key words: Education, women, gender social relations

\section{Referências}

BAUDELOT, Christian; ESTABLET, Roger. Allez les filles! Paris: Seuil, 1992. 244 p.

BERGER, Peter; LUCKMANN, Thomas. A construção social da realidade: tratado de sociologia do conhecimento. Petrópolis: Vozes, 1999. 247 p.

CARVAlHO, Marília Gomes de. Relações de gênero na família. Tecnologia e Humanismo, Curitiba, n. 17, p. 20-28, 1997.

DUBY, Georges; PERROT, Michelle (Orgs.). História das mulheres. Porto: Afrontamento, 1993. v. 2 - A Idade Média. p. 99-142.

DURU-BELLAT, Marie. L’école des filles. Paris : Harmattan, 1990. 232 p.

INSTITUTO NACIONAL DE ESTUDOS E PESQUISAS EDUCACIONAIS ANÍSIO TEIXEIRA. Dados Estatísticos. Disponível em: <http://www.inep.gov.br/estatisticas/>. Acesso em: 10 set. 2002.

MANOEL, Ivan Aparecido. Igreja e educação feminina (1859-1919): uma face do conservadorismo. São Paulo: UNESP, 1996. 102 p.

MAURO, Frédéric. La vie quotidienne au Brésil au temps de Pedro Segundo (1831-1889). Paris: Hachette, 1980. $316 \mathrm{p}$.

MOSCONI, Nicole. Femmes et savoir: la société, l'école et la division sexuelle des savoirs. Paris: Harmattan, 1994. $362 \mathrm{p}$.

ROUSSEAU, Jean-Jacques. Émile ou de l'éducation. Paris: Garnier-Flammarion, 1966. 629 p. 